\title{
Article \\ Characterization of Chirality in Diffractive Metasurfaces by Photothermal Deflection Technique
}

\author{
Roberto Li Voti ${ }^{1, *}$, Grigore Leahu ${ }^{1}$, Emilija Petronijevic ${ }^{1}\left(\mathbb{D}\right.$, Alessandro Belardini ${ }^{1}{ }^{(}$, Tiziana Cesca ${ }^{2}(\mathbb{D}$, \\ Carlo Scian ${ }^{2}$, Giovanni Mattei ${ }^{2}$ and Concita Sibilia ${ }^{1}$ \\ 1 Department of Basic and Applied Sciences for Engineering (SBAI), Sapienza Università di Roma, \\ Via A. Scarpa 14, I-00161 Rome, Italy; grigore.leahu@uniroma1.it (G.L.); \\ emilija.petronijevic@uniroma1.it (E.P.); Alessandro.belardini@uniroma1.it (A.B.); \\ concita.sibilia@uniroma1.it (C.S.) \\ 2 Physics and Astronomy Department, University of Padova, Via Marzolo 8, I-35131 Padova, Italy; \\ tiziana.cesca@unipd.it (T.C.); carlo.scian@unipd.it (C.S.); giovanni.mattei@unipd.it (G.M.) \\ * Correspondence: roberto.livoti@uniroma1.it; Tel.: +39-06-49916540
}

Citation: Li Voti, R.; Leahu, G.; Petronijevic, E.; Belardini, A.; Cesca, T.; Scian, C.; Mattei, G.; Sibilia, C. Characterization of Chirality in

Diffractive Metasurfaces by Photothermal Deflection Technique. Appl. Sci. 2022, 12, 1109. https:// doi.org/10.3390/app12031109

Academic Editor: Saulius Juodkazis

Received: 9 December 2021

Accepted: 16 January 2022

Published: 21 January 2022

Publisher's Note: MDPI stays neutral with regard to jurisdictional claims in published maps and institutional affiliations.

Copyright: (C) 2022 by the authors. Licensee MDPI, Basel, Switzerland. This article is an open access article distributed under the terms and conditions of the Creative Commons Attribution (CC BY) license (https:// creativecommons.org/licenses/by/ $4.0 /)$.
Featured Application: Photothermal characterization of chiro-optical phenomena in metasurfaces.

\begin{abstract}
Chirality, a lack of mirror symmetry, is present in nature at all scales; at the nanoscale, it governs the biochemical reactions of many molecules, influencing their pharmacology and toxicity. Chiral substances interact with left and right circularly polarized light differently, but this difference is very minor in natural materials. Specially engineered, nanostructured, periodic materials can enhance the chiro-optical effects if the symmetry in their interactions with circular polarization is broken. In the diffraction range of such metasurfaces, the intensity of diffracted orders depends on the chirality of the input beam. In this work, we combine a photothermal deflection experiment with a novel theoretical framework to reconstruct both the thermal and optical behavior of chiro-optical behavior in diffracted beams.
\end{abstract}

Keywords: chirality; diffraction; photothermal deflection technique; self-assembled metasurfaces

\section{Introduction}

A chiral object cannot be superimposed onto its mirror image; and thus has a left and right version, like our hands. Even though the physical properties of the two versions are equal, their interactions with the outside world depend on the "handedness". For example, by looking at the components of many commercial weed killers, some of them can act as a herbicide when in the proper handedness; while the other handedness is inactive [1]. Chirality governs the biochemical reactions of many important molecules, defining their pharmacology and toxicity; more than $50 \%$ of pharmaceuticals and $40 \%$ of agrochemicals are chiral $[2,3]$. The characterization of chirality involves an interaction of the chiral material with circularly polarized beams of the opposite handedness. The pioneering work was done by Pasteur, by studying the rotation of the polarization plane of linear polarized light travelling in chiral media, i.e., the optical rotatory power or optical activity (OA) [4]. This effect is due to the difference in the propagation velocity of two circularly polarized beams of opposite handedness, in which a linear polarized beam can be decomposed. Another aspect of interaction between chiral light and chiral substances is the differential absorption of the left and right circular polarized light (LCP from RCP, respectively), and this differential absorption is usually defined as circular dichroism (CD). Unfortunately, the CD of most molecules is extremely low and lies in the ultraviolet range; the absorption vanishes at small molecular concentrations [5,6]. One way to enhance CD is to exploit self-assembly processes in supramolecular chiral arrangements, as demonstrated in [7-11]. 
Another possibility is the coupling of molecules with chiral nanostructured substrates, as shown in [12].

Over the past few years, nanotechnology developments have enabled the fabrication of specially engineered nanostructured materials, which can confine and enhance chirooptical effects in the near- and far-field [13-16]. In parallel, scientists have been developing new methods to characterize chiro-optical effects at the nanoscale. Interestingly, unconventional measurements of chiral detection by means of photothermal phenomena are once again becoming topical. This is because of the definition of $\mathrm{CD}$, which would optimally require direct measurements of absorption to occur during the chiro-optical process. Such absorption, without the influence of scattering, was measured in nanostructures by means of a photo-acoustic technique [17-21]. On the other hand, the combination of a thermal lens and circular dichroism has led to very sensitive chiral analyses on microchips [22], which has further led to remarkable works on the CD microscopy of a single nanostructure [23,24]. Chiral photothermal effects in planar metamaterials have been numerically proposed for chiral bolometers [25], while photothermal chirality in Au helical nanoparticles has been measured by means of luminescence ratio thermometry [26].

Here, we show that the photothermal deflection technique (PDT) can be applied to study chiral photothermal effects in the diffraction range of metasurfaces, and that PDT results can be used to reconstruct thermal profiles, which depend on the excitation handedness. PDT is usually used for scattering-free and non-destructive characterization of different solid materials [27-30]. It was not until recently that scientist realized the new possibilities of using PDT to study thermal effects at the nanoscale, e.g., for plasmonenhanced solar cells [31], photon quantum yield in quantum dots [32], and phosphor with high photoluminescence efficiency [33]. We recently proposed a PDT setup as a cheaper and simpler alternative to diffraction spectroscopy: we measured chirality-dependent diffraction orders in asymmetric metasurfaces [34]. In the present work, we go deeper into this new methodology with respect to the work in [34]. In Section 3.1, we explore the limits of applicability, by lowering the modulation frequency to $16 \mathrm{~Hz}$, where the thermal diffusivity length is too large, causing undesired interference effects among the heat sources, and a lack of localization and identification of the diffracted orders. In Section 3.2, we develop an analytical model to acquire a quick estimate of the spatial position of the diffracted orders. In Section 3.3, we calculate the temperature rise of all the diffractive orders at both $514 \mathrm{~nm}$ and $458 \mathrm{~nm}$ laser excitation wavelengths. We show a detailed theory of the reconstruction of thermal effects from the PDT signal. Specifically, we use the amplitude and phase data of the PDT signal, which are a consequence of handednessdependent beam diffracted by the metasurface. We reconstruct the thermal profile formed by a number of diffracted beams and show how they depend on the chirality of diffraction and we show a 3D plot of the absorbed power distribution on the metasurface. Moreover, we retrieve the average thermal properties of the metasurface, such as the diffusivity and spot size of all diffracted beams. In [34], we laid the foundations for a new type of application of the PDT technique at the nanoscale, and here we show the potentiality of the technique to investigate different aspects of the characterization of nanostructures, paving the way for further applications.

\section{Materials and Methods}

\subsection{PDT Characterization of Metasurfaces}

We investigated the same Ag-based metasurface from [34]; a photograph is shown in the top left inset of Figure 1. It was fabricated using low-cost nanosphere lithography [35], and a tilted deposition of $50 \mathrm{~nm}$ of $\mathrm{Ag}$ at $45^{\circ}$ [20,36,37]. The sample was based on an hexagonal array of polystyrene nanospheres; the periodicity of the array and the diameter of the nanospheres were $522 \mathrm{~nm}$, and $370 \mathrm{~nm}$, respectively, and the metasurface lay on a $1 \mathrm{~mm}$ glass substrate. The tilted Ag deposition defined the asymmetric Ag shell, as well as the elliptical nanohole array (ENHA) [38] on the substrate. The geometry of such a metasurface led to diffraction orders for the wavelengths below its periodicity. Therefore, 
if such sample gets excited with an Ar pump beam, the light will be diffracted into welldefined orders. The intensity of these orders depends on the pump beam polarization, as the metasurface has asymmetric nanoshells and ENHA.

In Figure 1 we show a sketch of the PDT experiment, based on bringing the diffracted orders back to the surface. Namely, if the sample is placed on a mirror, the metasurface diffracts the beams to the glass, where they get reflected from the mirror, travel back to the sample surface, and are finally absorbed by the metal. Six diffracted orders and the zeroth order get absorbed by the metal on the surface, where they create heat sources. Each heat source creates a local gradient of temperature, which deflects a probe-beam. Therefore, the deflected signal is a measure of the induced heat, which depends on the intensity of the diffracted order, and, thus, on the chirality of the pump beam. The bottom left inset in Figure 1 shows a simple photograph of the diffracted orders of the sample, where the pump beam at $514 \mathrm{~nm}$ excited the sample at a normal incidence. Six clear orders exit in the positions of the hexagon vertices, while the back-reflected, zeroth order exits at the center. In Figure 1, this beam is omitted as it is superimposed on the pump beam.

PDT exhibits a very high absorption sensitivity in solids, of the order of $10^{-7} \mathrm{~cm}^{-1}[28,39]$. In this work, we measured diffraction-induced absorption at different wavelengths using an argon beam (Coherent Innova 70): at $458 \mathrm{~nm}, 496 \mathrm{~nm}$, and $514 \mathrm{~nm}$. The pump beam's intensity was mechanically modulated at low modulation frequencies. In this work, we reported the PDT data obtained at $16 \mathrm{~Hz}$ and $36 \mathrm{~Hz}$. This beam passed through a linear polarizer and a quarter wave plate, thus becoming circularly polarized with LCP or RCP. For the probe beam, we used a He-Ne laser (Spectra Physics). This beam passed through the air above the surface, traveling in the y-direction, where it was deflected by the thermal gradients arising from the aforementioned diffracted orders. A 2D position sensor detected this deflection and connected it to a lock-in amplifier; thus, giving both the PDT amplitude and phase as a result. Moreover, we controlled the pump-probe distance using a motorized translation stage.

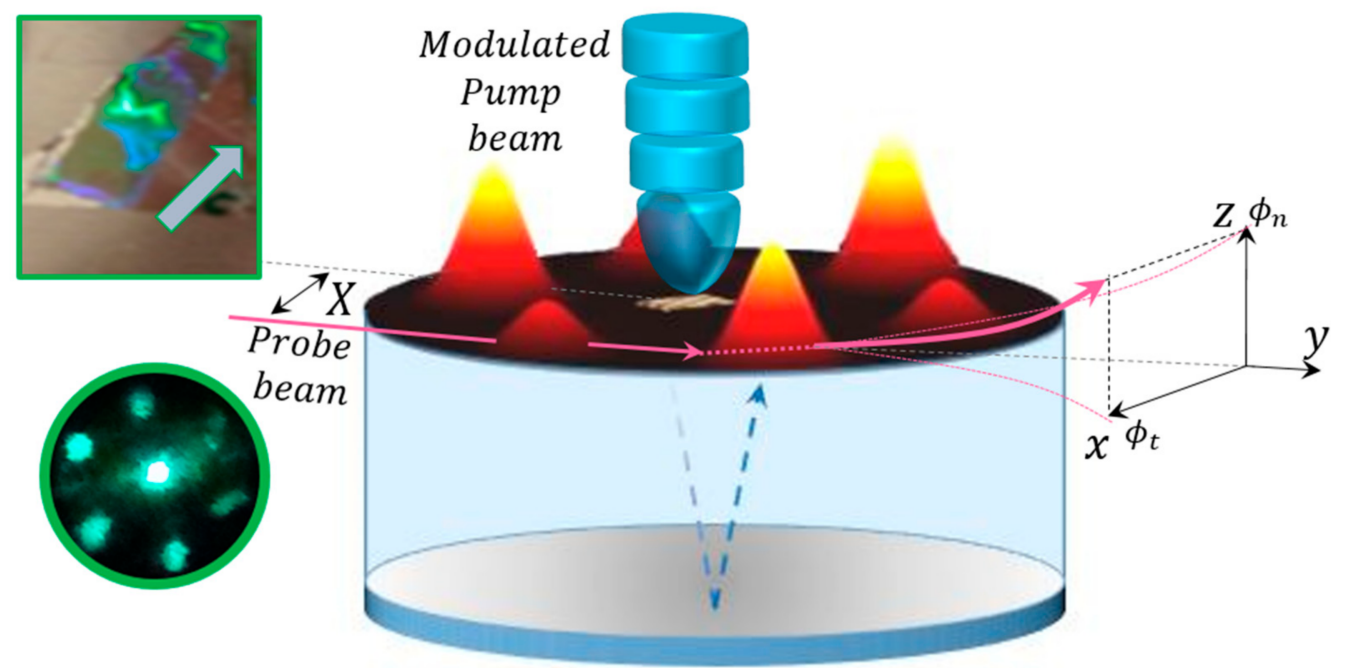

Figure 1. Simplified schematic of the photothermal deflection measurements of diffracted orders. Top left inset: photo of the sample. Bottom left inset: photo of the diffracted orders in Ag-plasmonic semi-nanoshell arrays (Ag-SNSA) metasurface when a pump beam at $514 \mathrm{~nm}$ excites it.

\subsection{Optical Simulations of the Metasurface}

Here, we combined two different numerical approaches to study both the diffraction of the metasurface, and its consequences on absorption. We previously used a commercial 3D finite difference time domain (FDTD) solver in Lumerical [40] to explain the PDT experimental data by looking at the diffraction effects at the nanoscale [34]. The 3D geometry of the sample is shown in Figure 2a; the polystyrene-based metasurface is covered by asymmetric plasmonic shells, and there is an obvious ENHA layer on the substrate, as 
can be seen from the SEM images in our previous works [20,34]. Figure $2 b$ shows a top view of our sample, which has the in-plane tilt with respect to the unit-cell boundaries (given by the surface $a \cdot a \sqrt{3}$ ). In the first step of the simulation, we applied the procedure from [34]. As in the experiment, the metasurface was excited by the LCP or RCP beam from the top (from the air side), diffracting this beam to the zeroth and higher orders. In Figure $2 \mathrm{c}$ we show the path of one of these orders, in order to explain two different simulations. The near-to-far field transformation below the metasurface gives the factor $\rho_{\text {diff }}$, which is the fraction of the incident power that gets diffracted to this order. It also gives the angle, $\theta_{\text {diff }}$, of the diffraction. Due to the chirality of the pump-metasurface interaction, $\rho_{\text {diff }}$ depends on the handedness of the pump, while $\theta_{\text {diff }}$ does not depend on it. The second step, instead, involved computation of the total absorption in the unit cell, after the previous beam was reflected from the underlying mirror. In this simulation, we excited the metasurface from the bottom, at an incidence angle of $\theta_{\text {diff }}$, and calculated the absorption per unit volume as $\rho_{a b s}=-0.5 \omega^{2}|\vec{E}|^{2} \operatorname{Im}\{\varepsilon\}$; at frequency $\omega$, the electric field intensity was detected by a 3D field monitor, while the Ag material parameters were taken from ellipsometric measurements [28]. The result of this simulation was a 3D absorption distribution in the unit-cell. However, this result was scaled with the $\rho_{\text {diff }}$ factor, as the intensity of the incident beam in the second simulation depended on its diffraction factor, $\rho_{\text {diff }}$.
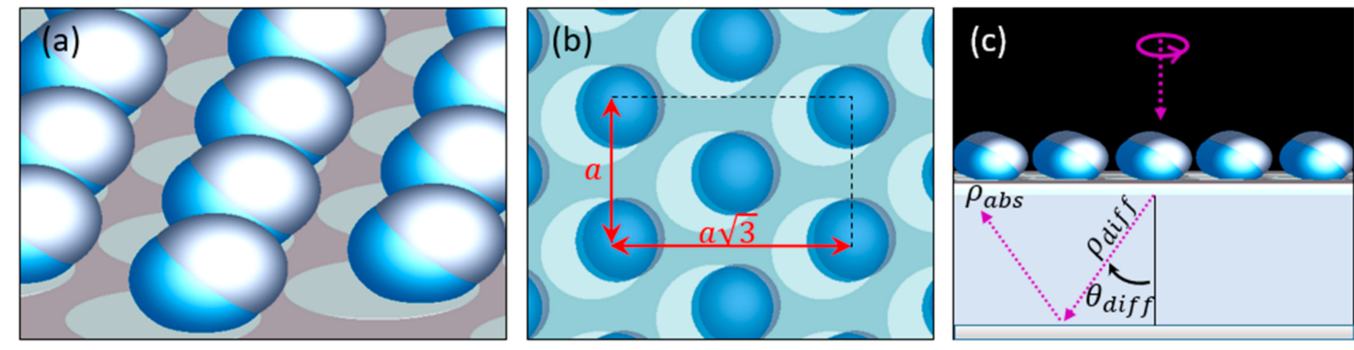

Figure 2. Schematic of numerical simulations: (a) 3D geometry of the sample; (b) top view of the metasurface; (c) schematic of the two different processes during the numerical modeling.

\section{Results}

\subsection{Experimental Results Using PDT}

The photothermal deflection technique has been applied by changing different parameters of the Ar pump beam: laser wavelengths $(458,496$, or $514 \mathrm{~nm})$; circular polarization orientations (LCP or RCP); angle of incidence ( 0 or $20 \mathrm{deg})$; and chopper modulation frequency $(16$ or $36 \mathrm{~Hz})$.

The typical photothermal deflection amplitude response, where the probe beam scans along the metasurface, is shown in Figure 3. The PDT scan contains a number of " $\mathrm{M}$ " shape signals, allowing the detection of heat sources found along the probe beam path (see Figure 4a). Each " $M$ " shape corresponded to the local thermal gradients produced by the incident pump beam (i.e., the largest signal at $d=0$ ), and by several diffracted orders, which could be localized and identified with the integer $m=1,2, \ldots, 6$, according to the anticlockwise numeration introduced in Figures 4 and 5, as described in the next section. Each " $\mathrm{M}$ " shape is due to the lateral deflection of the probe beam being proportional to the lateral thermal gradient; it is zero exactly above the center of the heat source, where a local maximum of the temperature rise occurs. On the contrary, it reaches its maximum amplitude at a distance of approximately one Gaussian beam width, from both sides of the beam center (see Figure 4b) [34].

Figure 3a,c shows the PDT amplitude signals for normal incidence excitation at $458 \mathrm{~nm}$ and $514 \mathrm{~nm}$, respectively. In both cases, all six existing diffracted orders were clearly visible from scanning the surface, from $-2.5 \mathrm{~mm}$ to $+2.5 \mathrm{~mm}$ (with respect to the incident pump beam position at $d=0$ ). The position of the center of each diffracted order can be calculated from the zeroes of the lateral deflection reported in Table 1. Moreover, the chiral response 
of the structure was tested, sending left or right circular polarized incident pump beams. In Figure 3, the LCP and RCP responses are in blue and red, respectively.

By comparing Figure $3 a, c$, one may note that:

(i) With a wavelength increase, the diffraction pattern enlarges due to the dispersion law of the glass refractive index, which spreads out the diffracted orders according to wavelength (see Figure 4c). This can be appreciated from the numerical simulations of the diffraction behavior of the different wavelengths, when the sample was excited at a normal incidence with an RCP beam (see Video S1 in the Supplementary Material).

(ii) The chiral response and the circular dichroism (i.e., difference between red and blue curves) was negligible at $458 \mathrm{~nm}$, though it became relevant for diffracted orders at $514 \mathrm{~nm}$, as is shown in the next session in Figure 6. Numerical simulations of the diffraction for different angles of the quarter wave plate are shown in Videos S2 and S3 in the Supplementary Materials.

Figure $3 \mathrm{~b}$,d shows the PDT amplitude signals at $458 \mathrm{~nm}$ and $514 \mathrm{~nm}$, for excitation under an oblique incidence at 20 degrees with respect to the norm. The following considerations can be made in this case:

(iii) The main heat source corresponding to the incident beam is always at $d=0$.

(iv) The secondary heat source, which is always visible at $d=-0.47 \mathrm{~mm}$, is a specularly reflected (SR) beam, corresponding to the zeroth order of the pump beam; this beam also gets transmitted to the glass, reflects back from the mirror, and eventually gets absorbed at the surface. The distance of $0.47 \mathrm{~mm}$ between SR peak and the main peak is compatible with the pump inclination of 20 degrees (in air), which becomes $\theta=13.2$ degrees in glass, producing a secondary heat spot at $d=2 L \tan (\theta)=0.47 \mathrm{~mm}$, where $L=1 \mathrm{~mm}$ is the glass thickness (see Figure 4c).

(v) Only two diffracted orders are clearly visible on the right side with respect to the pump beam. The other orders fall outside the pump-probe offset range, as is described in the next section and shown in Table 2.

(vi) The chiral response and circular dichroism for the diffracted orders is enhanced for both wavelengths.

(vii) The "M" shape, produced at the modulation frequency of $f=16 \mathrm{~Hz}$ (Figure 3b,d), is wider that the one at $f=36 \mathrm{~Hz}$ (Figure $3 \mathrm{a}, \mathrm{c}$ ). The reason for this is in the different thermal spread of the absorbed light beam; the heat sources are more localized at a high frequency, where the diffusion process outside the spot size is inhibited. For such a reason the choice of $f=16 \mathrm{~Hz}$ is not recommended for thermal imaging, representing the limits of such a technique in the present geometry, causing undesired interference effects among the heat sources, and a lack of localization and identification of the diffracted orders [34].

\subsection{Heat Sources Localization from PTD Data}

In this section we present a simple geometrical model to allow the clear interpretation of the PTD experimental data, giving a quick quantitative estimate of the main parameters of the pump beam diffraction patterns. First, we analyzed the case of a normal incidence. The Ar pump beam produced six diffracted beams, which were reflected by the back mirror, and absorbed by the metasurface, eventually forming a regular hexagonal pattern of heat sources, as shown in Figure 3a.

The He-Ne probe beam travels in air, skimming the metasurface along the y-axis at a minimum height (z) from the sample surface (typically 20-50 $\mu \mathrm{m}$ ), so as to probe the heat sources induced by the pump beam (Figure $4 \mathrm{~b}$ ). The theory of PDT in a transverse configuration states that the probe beam is deflected from its original trajectory due to the air's thermal gradient, produced by the heat source (mirage effect). The lateral deflection angle, $\Phi_{x}$, is accumulated along the probe beam path, and is eventually detected by a photodiode position sensor. Quantity $\Phi_{x}$ is given by the well-known expression [27,39]:

$$
\Phi_{x}=\frac{1}{n} \frac{d n}{d T} \int_{y} \frac{d T}{d x} d y
$$


where, in air, the refractive index is $n \approx 1$ and the optothermal coefficient in air at room temperature is $d n / d T \approx-10^{-6} \mathrm{~K}^{-1}$.

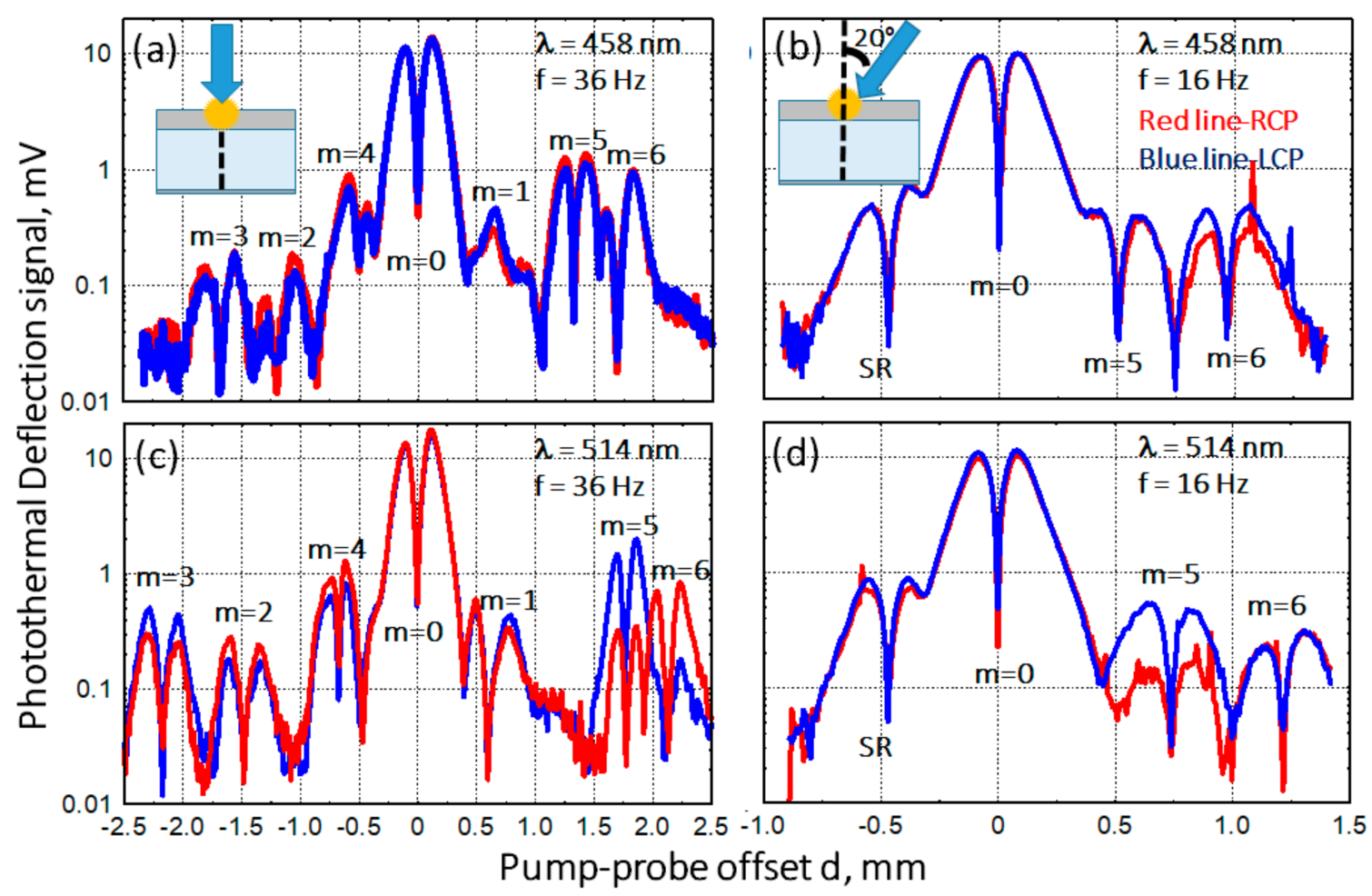

Figure 3. Amplitude of the photothermal deflection vs. pump-probe offset on Ag-SNSA sample excited with an Ar pump beam under different conditions: (a) normal incidence, wavelength $\lambda=458 \mathrm{~nm}$; modulation frequency $36 \mathrm{~Hz}$; (b) oblique incidence at $20 \mathrm{deg}$, wavelength $\lambda=458 \mathrm{~nm}$; modulation frequency $16 \mathrm{~Hz}$; (c) normal incidence, wavelength $\lambda=514 \mathrm{~nm}$; modulation frequency $36 \mathrm{~Hz}$; (d) oblique incidence at $20 \mathrm{deg}$, wavelength $\lambda=514 \mathrm{~nm}$; modulation frequency $16 \mathrm{~Hz}$. Red and blue lines indicate RCP and LCP responses, respectively.

It is worth noting that each heat source exhibits a regular elliptical shape (Figure 4a), reaching the maximum temperature in the center of the ellipse. By scanning the probe along the $\mathrm{x}$-axis, the deflection angle will show an anti-symmetrical behavior with $x$, becoming zero where the probe passes along the heat source center, corresponding to the maximum temperature increase (see Figure $4 \mathrm{~b}$ ).

We were able to measure the absorption-induced PDT for all seven heat sources (incident + six diffracted orders), at the same time, by properly misaligning the probe beam and the symmetry lines of the hexagonal diffraction pattern (see Figure $4 \mathrm{a}$ ) and then scanning the probe beam from $-2.5 \mathrm{~mm}$ to $+2.5 \mathrm{~mm}$ using a translation stage. The position of each heat source center was calculated from the condition $\Phi_{x}=0$, and is reported in Table 1 for each diffracted order $\mathrm{m}$, as well as for three different wavelengths.

From simple geometrical considerations, taken from Figure $3 a$, the position of the heat sources are linked to each other by the following relationship:

$$
\left\{\begin{array}{l}
d_{1}=R \sin \left(\frac{\pi}{6}-\alpha\right) \\
d_{5}=R \sin \left(\frac{\pi}{6}+\alpha\right) \\
d_{6}=R \cos (\alpha)
\end{array}\right.
$$

where the misalignment angle can be calculated as $\alpha=\arctan \left(\frac{1}{\sqrt{3}} \frac{d_{5}-d_{1}}{d_{6}}\right) \approx 15^{\circ}$ averaged for all wavelengths. By combining the equations, one may calculate the side $R$ of the hexagon pattern as $R=d_{6} / \cos \alpha$, while the internal angle of the diffracted beams is obtained by $\theta=\arctan (R / 2 L)$, where $L=1 \mathrm{~mm}$ is the thickness of the glass substrate 
(see Figure 4c). These last two quantities are calculated for the three wavelengths and are shown in Table 1 . Note that the calculated internal angles are in good agreement with the theoretical prediction for the $2 \mathrm{D}$ photonic crystals given by $\theta(\lambda)=\arcsin \left(\frac{2}{\sqrt{3}} \frac{\lambda / n}{a}\right)$ (where $a=522 \mathrm{~nm}$ is the period of the hexagonal 2D close packed structure and $n=1.5$ is the glass refractive index).

Table 1. Normal incidence: geometrical parameters of the heat sources produced by the absorption of the diffracted beams, as calculated from PDT data.

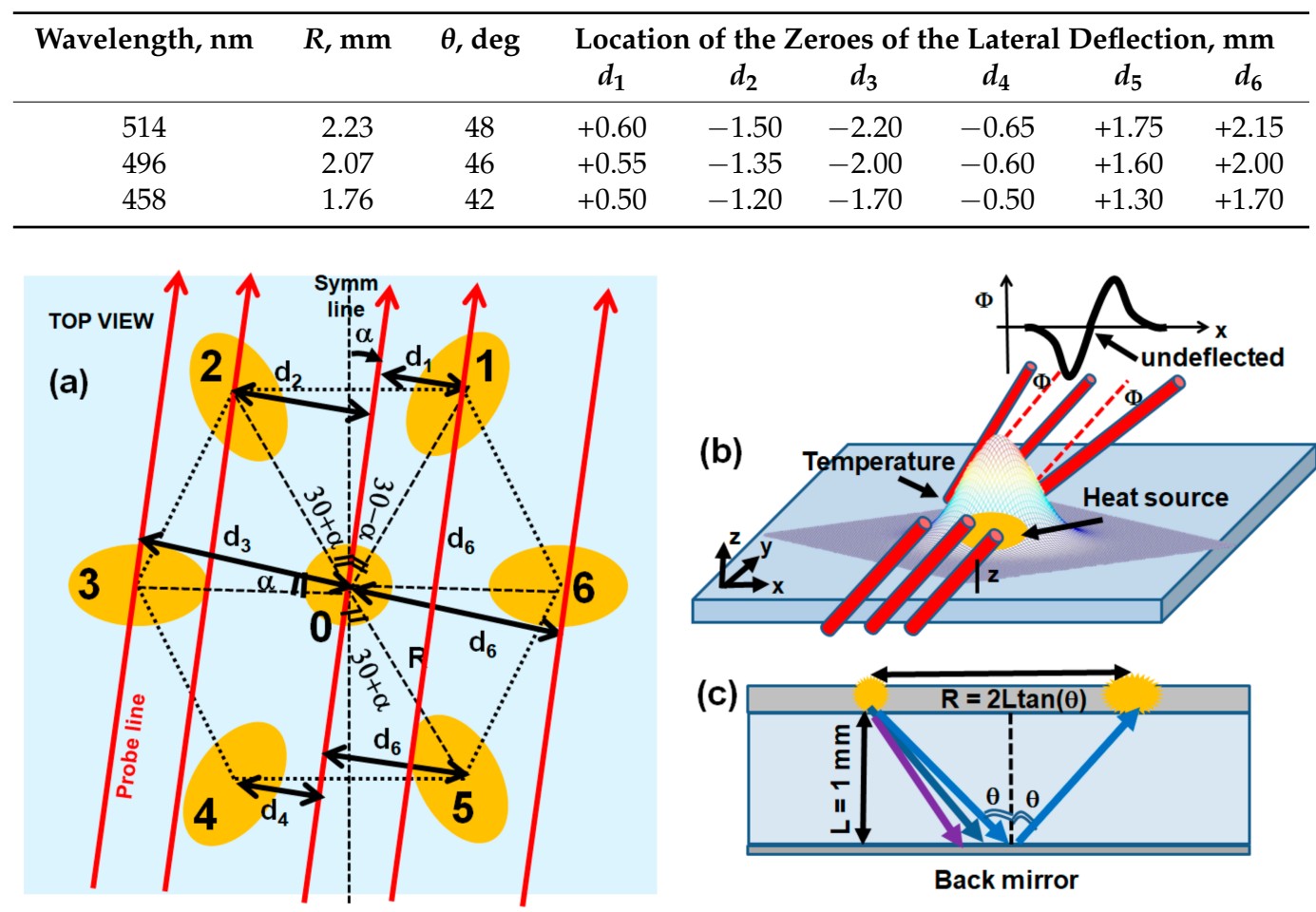

Figure 4. Scheme of the photothermal deflection measurements of the diffracted orders. (a) Top view. Example of zeroes of the lateral deflection signal when the probe beam is passing above the center of the heat source produced by the diffracted orders; (b) typical antisymmetric behavior of the lateral beam deflection; (c) lateral view. Propagation of one diffracted order and the formation of the surface heat source.

A different situation is found in case where the pump beam is incidental to the sample at angle $\theta_{\text {air }}=20 \mathrm{deg}$ with respect to the norm of the metasurface, in the x-direction (transverse to the probe beam path). In this case, the incident beam is represented by wavevector $k_{x, \text { air }}=-\frac{2 \pi}{\lambda} n_{\text {air }} \sin \theta_{\text {air }}$ (with $n_{\text {air }} \approx 1$ ) along the k-vector surface plane, as shown in Figure $4 \mathrm{a}$. In 2D photonic crystals, the k-vectors of the six diffracted beams can be calculated by adding wavenumber $\frac{4 \pi}{a \sqrt{3}}$, due to the metasurface hexagonal periodical pattern (where $a=522 \mathrm{~nm}$ is the period of the hexagonal, 2D, close-packed structure).

$$
\left\{\begin{array}{l}
k_{x, m}=-\frac{2 \pi}{\lambda} n_{\text {air }} \sin \theta_{\text {air }}+\frac{4 \pi}{a \sqrt{3}} \cos \left(m \frac{\pi}{3}\right) \\
k_{y, m}=+\frac{4 \pi}{a \sqrt{3}} \sin \left(m \frac{\pi}{3}\right)
\end{array}\right.
$$

where $m=1,2, \ldots, 6$ is the integer corresponding to the $m$-th diffracted beam. The in-plane direction of each wavevector is identified by angle $\beta_{m}$, and may be calculated with respect to the $k_{x}$ direction, according to the relationship (see Figure 5a).

$$
\beta_{m}=\arctan \left(\frac{k_{y, m}}{k_{x, m}}\right)=\arctan \left(\frac{\sin \left(m \frac{\pi}{3}\right)}{\cos \left(m \frac{\pi}{3}\right)-\frac{\sqrt{3}}{2} \frac{a}{\lambda} n_{\text {air }} \sin \theta_{\text {air }}}\right)
$$


From Equation (4), the angles are calculated and reported in Table 2. It is worth noting that the incident angle of $\theta_{\text {air }}=20$ deg already causes a relevant displacement from the symmetric case $\theta_{\text {air }}=0 \mathrm{deg}$, where $\beta_{m}=m \cdot \pi / 3$. Once the $\mathrm{k}$ vector is calculated in the xy plane, the internal inclination angle in substrate $\theta_{m}$ can be easily obtained by imposing the conservation of the wavevector at surface $\mathrm{z}=0: k_{x y, m}=\sqrt{k_{x, m}^{2}+k_{y, m}^{2}}=\frac{2 \pi}{\lambda} n \sin \theta_{m}$, which gives:

$$
\theta_{m}=\arcsin \left(\frac{1}{n} \sqrt{\left(\frac{2}{\sqrt{3}} \frac{\lambda}{a}\right)^{2}-2\left(\frac{2}{\sqrt{3}} \frac{\lambda}{a}\right) \cos \left(m \frac{\pi}{3}\right) n_{\text {air }} \sin \theta_{\text {air }}+\left(n_{\text {air }} \sin \theta_{\text {air }}\right)^{2}}\right)
$$

from internal angle $\theta_{m}$, one may calculate the distance $\left(R_{m}\right)$ between the location of the heat source corresponding to the $\mathrm{m}$-th diffracted beam and the incident beam, as follows (see Figure $5 b)$ :

$$
R_{m}=2 L \tan \theta_{m}
$$

Table 2 shows that the quantities $\left(R_{m}\right)$ are different from each other. A small group of beams for $m=1,5$ and 6 are absorbed very close to the incident beam, due to the small internal angle. The pump-probe offset, $d_{m}$, during the probe beam scan can be calculated from the previous results, looking at the sketch in Figure $5 \mathrm{~b}$, and according to the following formula:

$$
d_{m}=R_{m} \cos \left(\beta_{m}+\alpha\right)
$$

where quantity $\alpha=15 \mathrm{deg}$ is the misalignment angle calculated from Equation (2). Table 2 summarizes all the geometrical results. A good agreement is found for the experimental data shown in Figure $3 b$,d. The diffracted beam for $m=1$ is hidden by the heat source of the pump beam located at $d=0$. The diffracted beams for $m=5$ and 6 are clearly visible for $d>0$. The orders $m=2,3,4$ fall at $d<0$, but are too far from the center and cannot be seen. In Figure $3 b, d$, one can find an additional heat source that is always at $d=-0.47 \mathrm{~mm}$, corresponding to the specular reflection, which is wavelength independent.
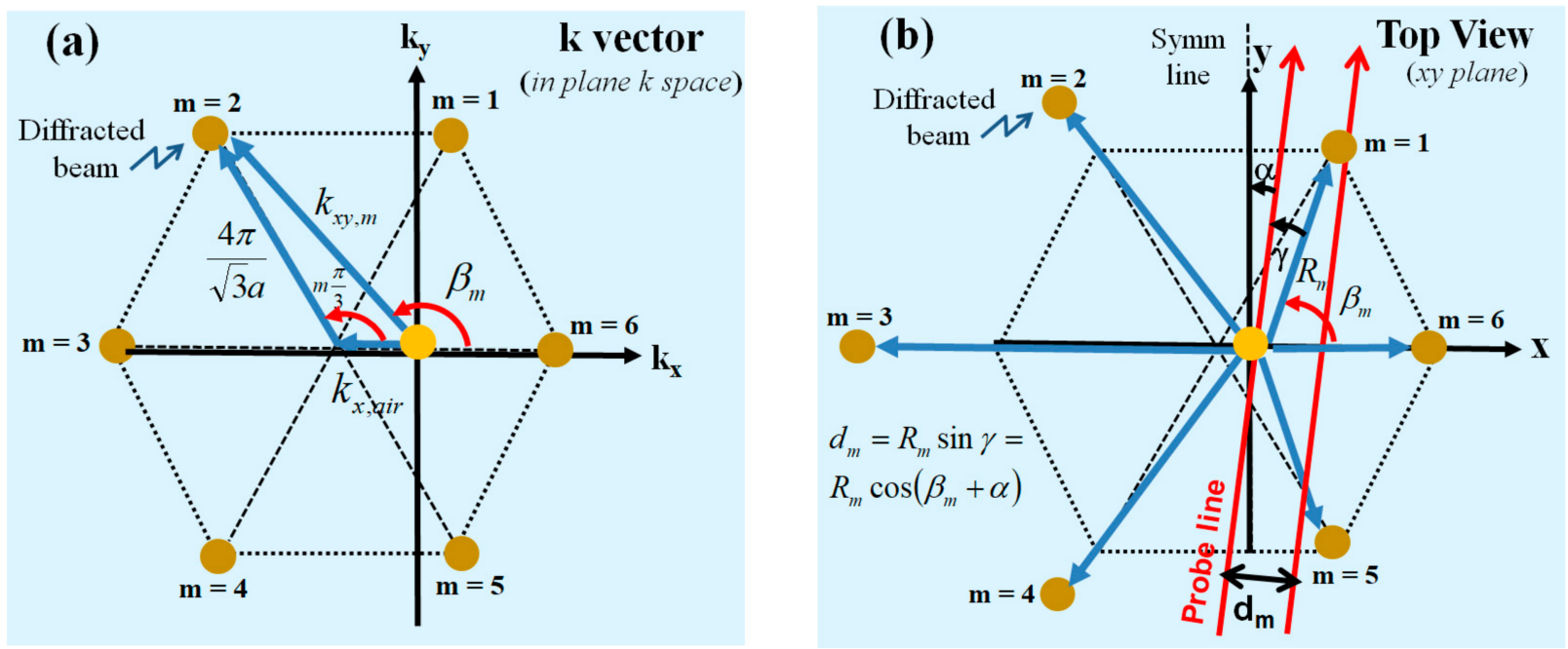

Figure 5. (a) Geometric representation of the diffracted beams in the k space; (b) Location of the heat sources in the real space (xy plane). 
Table 2. Oblique incidence: theoretical expectation of the geometrical parameters of the heat sources produced by the absorption of the diffracted beams.

\begin{tabular}{|c|c|c|c|c|c|c|c|}
\hline \multirow{2}{*}{ Wavelength, nm } & \multirow{2}{*}{ Quantity } & \multicolumn{6}{|c|}{ Diffraction Order m } \\
\hline & & 1 & 2 & 3 & 4 & 5 & 6 \\
\hline \multirow{4}{*}{514} & $R, \mathrm{~mm}$ & 1.78 & 3.78 & 8.93 & 3.78 & 1.78 & 1.22 \\
\hline & $d, \mathrm{~mm}$ & $+0.01^{2}$ & -3.13 & -8.70 & -1.89 & $+0.77^{1}$ & $+1.19^{1}$ \\
\hline & $\beta, \operatorname{deg}$ & 77 & 133 & 180 & 227 & 283 & 0 \\
\hline & $\theta, \operatorname{deg}$ & 42 & 62 & 77 & 62 & 42 & 31 \\
\hline \multirow{4}{*}{496} & $R, \mathrm{~mm}$ & 1.66 & 3.36 & 6.08 & 3.36 & 1.66 & 1.14 \\
\hline & $d, \mathrm{~mm}$ & $-0.03^{2}$ & -2.79 & -5.93 & -1.69 & $+0.70^{1}$ & $+1.11^{1}$ \\
\hline & $\beta, \operatorname{deg}$ & 78 & 133 & 180 & 227 & 282 & 0 \\
\hline & $\theta, \operatorname{deg}$ & 40 & 59 & 72 & 59 & 40 & 30 \\
\hline \multirow{4}{*}{458} & $R, \mathrm{~mm}$ & 1.45 & 2.72 & 4.00 & 2.72 & 1.45 & 0.98 \\
\hline & $d, \mathrm{~mm}$ & $-0.07^{2}$ & -2.28 & -3.90 & -1.41 & $+0.57^{1}$ & $+0.95^{1}$ \\
\hline & $\beta, \operatorname{deg}$ & 80 & 134 & 180 & 226 & 280 & 0 \\
\hline & $\theta, \operatorname{deg}$ & 36 & 54 & 63 & 54 & 36 & 26 \\
\hline
\end{tabular}

${ }^{1}$ The scan in Figure $3 \mathrm{~b}, \mathrm{~d}$ are from $\mathrm{d}=-1 \mathrm{~mm}$ to $1.5 \mathrm{~mm}$; only $m=5$ and $m=6$ fall in such a range. ${ }^{2}$ The diffracted order $m=1$ cannot be seen because it is hidden by the central heat source at $d=0$.

\subsection{Determination of the Induced Temperature of the Metasurface}

It is well known that the photothermal deflection technique, in the transverse configuration, is extremely sensitive to the thermal gradients induced in the air layer in contact with the metasurface (at a minimum height of $\mathrm{z} \approx 20-50 \mu \mathrm{m}$ ) (see Equation (1)). The 1D map of the lateral heat flux induced by the incident pump and the diffracted beams can be obtained simply by performing a probe beam scan, as shown in Figures 3 and $5 \mathrm{~b}$. Moreover, by analyzing both the PTD amplitude and the phase signals in the proximity of each heat source $(<0.3 \mathrm{~mm})$, recent articles demonstrated that the temperature map of each individual heat source can be accurately estimated by applying inverse methods [41-44]. In fact, in the case of a heat source with a cylindrical symmetry, Equation (1) can be inverted to obtain the surface temperature increase from the following inverse integral transformation $[34,45,46]$ :

$$
T(r)=-\frac{1}{\pi}\left(\frac{1}{n} \frac{d n}{d T}\right)^{-1} \int_{r}^{\infty} \frac{\Phi_{x}(x)}{\sqrt{x^{2}-r^{2}}} d x
$$

where $1 / n(d n / d T) \approx-10^{-6}{ }^{\circ} \mathrm{C}^{-1}$, and $\mathrm{r}$ is the radial distance from the heat source (the extension to elliptical heat sources is also allowed). We applied Equation (8) to process the PTD data in Figure 3, separately, for each heat source within the spatial range of $0.3 \mathrm{~mm}$. As an example, Figure 6 shows a reconstructed surface temperature profile, produced by the incident pump beam of $40 \mathrm{~mW}(m=0)$ and by the diffracted beams with an index of $m=2,3,5,6$ for normal incidence at wavelengths $514 \mathrm{~nm}$ and $458 \mathrm{~nm}$, and at $\mathrm{f}=36 \mathrm{~Hz}$.

The temperature profiles exhibit Gaussian-like shapes and the spot-sizes are shown in Figure 6 and reported in Tables 3 and 4. It is worth noting that, for $m=0$, the temperature profile of the incident beam is superimposed, with a secondary source produced by the beam itself when reflected by the mirror and re-absorbed at the surface with a weak lateral shift of $0.07 \mathrm{~mm}$ due to a small misalignment. The maximum temperature increase is estimated at around $11^{\circ} \mathrm{C}$, independent of the wavelength and the kind of incident pump beam chirality.

Chirality has been tested on the temperature induced by the diffracted beams. Looking at Figure 6, chirality is rather irrelevant at a wavelength of $458 \mathrm{~nm}$, while it becomes clearly observable at a wavelength of $514 \mathrm{~nm}$ for $m \neq 0$. In particular, a change in the sign of chirality is also visible for all the orders (see $m=2,3,5,6$ ). One reason for this could be the increase in the internal angle of the diffracted beams from 42 deg at $458 \mathrm{~nm}$ to 48 deg at 
$514 \mathrm{~nm}$, which, from numerical simulations, seems responsible for the enhancement of the chirality in this structure (see Table 1).
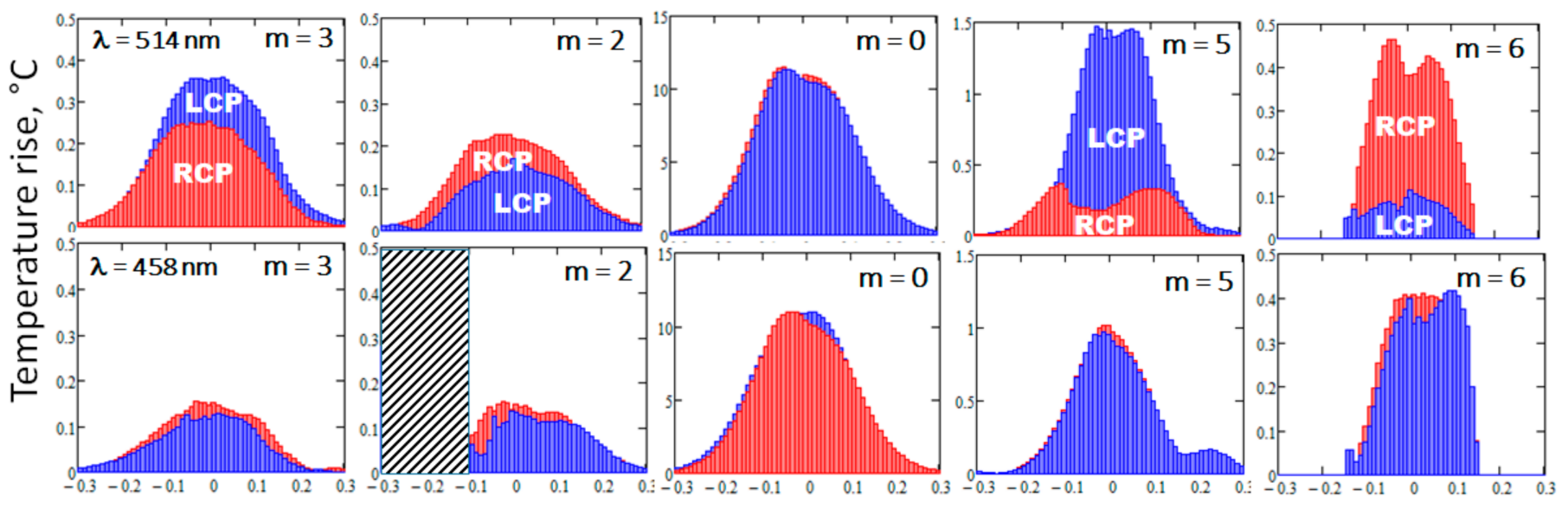

Offset, $\mathrm{mm}$

Figure 6. Temperature rise induced by the absorption of the pump beam and diffracted beams and calculated using Equation (8) from the PDT data in Figure 3c at $514 \mathrm{~nm}$, and Figure 3a at $458 \mathrm{~nm}$. The temperature profile is plotted for several diffracted beams. For all figures, the red and blue bars stand for RCP and LCP, respectively.

The values of the maximum temperature rise and chirality are reported in Table 3 for each heat source, for both 514 and $458 \mathrm{~nm}$. Circular dichroism as a percentage is calculated from the temperature peaks as $C D \%=100 \%\left(T_{L C P}-T_{R C P}\right) /\left(T_{L C P}+T_{R C P}\right)$. The values of $C D$ agree with those reported in $[13,26]$. Results for $m=1$ are missing because the signals from the heat source are hidden by the higher signal coming from source $m=0$, and Equation (8) cannot be applied. Results for $m=2$ at $458 \mathrm{~nm}$ are only partially plotted due to data corruption, and interference effects with the heat source for $m=3$ in Figure 3a.

Finally, we apply the numerical method from Section 2.2 to visualize the power absorbed in the unit cell at $514 \mathrm{~nm}$, at a normal incidence, for orders 5 and 6 (from Figure 6). In Figure 7, we confirm that, when the metasurface is excited with LCP, the order with $m=5$ results in higher absorption in the unit cell than for the RCP excitation. The opposite behavior is found for the order with $m=6$. We can clearly see that this order results in higher absorption in the unit cell, especially in the volume of the ENHA. In conclusion, numerical simulations of the single metasurface unit cell are in good agreement with the thermal reconstruction from the PDT data.

Table 3. Maximum local temperature rise for each diffracted order, as calculated by Equation (8) from PDT data in Figure 3, for excitation at 514 and $458 \mathrm{~nm}$. The peak temperature is calculated for both $\mathrm{RCP}$ and LCP. Circular dichroism in percentage $(\mathrm{CD} \%)$ is calculated from the temperature peaks as $100 \%\left(T_{L C P}-T_{R C P}\right) /\left(T_{L C P}+T_{R C P}\right)$. The input pump beam power is $40 \mathrm{~mW}$.

\begin{tabular}{ccccccccc}
\hline \multirow{2}{*}{ Wavelength, nm } & Peak Temp & Pump & \multicolumn{7}{c}{ Diffraction Order m } \\
& & $\mathbf{0}$ & $\mathbf{1}$ & $\mathbf{2}$ & $\mathbf{3}$ & $\mathbf{4}$ & $\mathbf{5}$ & $\mathbf{6}$ \\
\hline \multirow{3}{*}{514} & $T_{R C P}{ }^{\circ} \mathrm{C}$ & 11.5 & - & 0.22 & 0.25 & 0.98 & 0.38 & 0.45 \\
& $T_{L C P}{ }^{\circ} \mathrm{C}$ & 11.5 & - & 0.16 & 0.35 & 0.78 & 1.47 & 0.10 \\
& $\mathrm{CD}, \%$ & 0 & - & -16 & 17 & -11 & +59 & -64 \\
\hline \multirow{3}{*}{458} & $T_{R C P}{ }^{\circ} \mathrm{C}$ & 11.0 & - & 0.16 & 0.15 & 0.75 & 1.02 & 0.41 \\
& $T_{L C P}{ }^{\circ} \mathrm{C}$ & 11.0 & - & 0.14 & 0.13 & 0.71 & 0.98 & 0.41 \\
& $\mathrm{CD}, \%$ & 0 & - & -6 & -7 & -3 & -2 & 0 \\
\hline
\end{tabular}




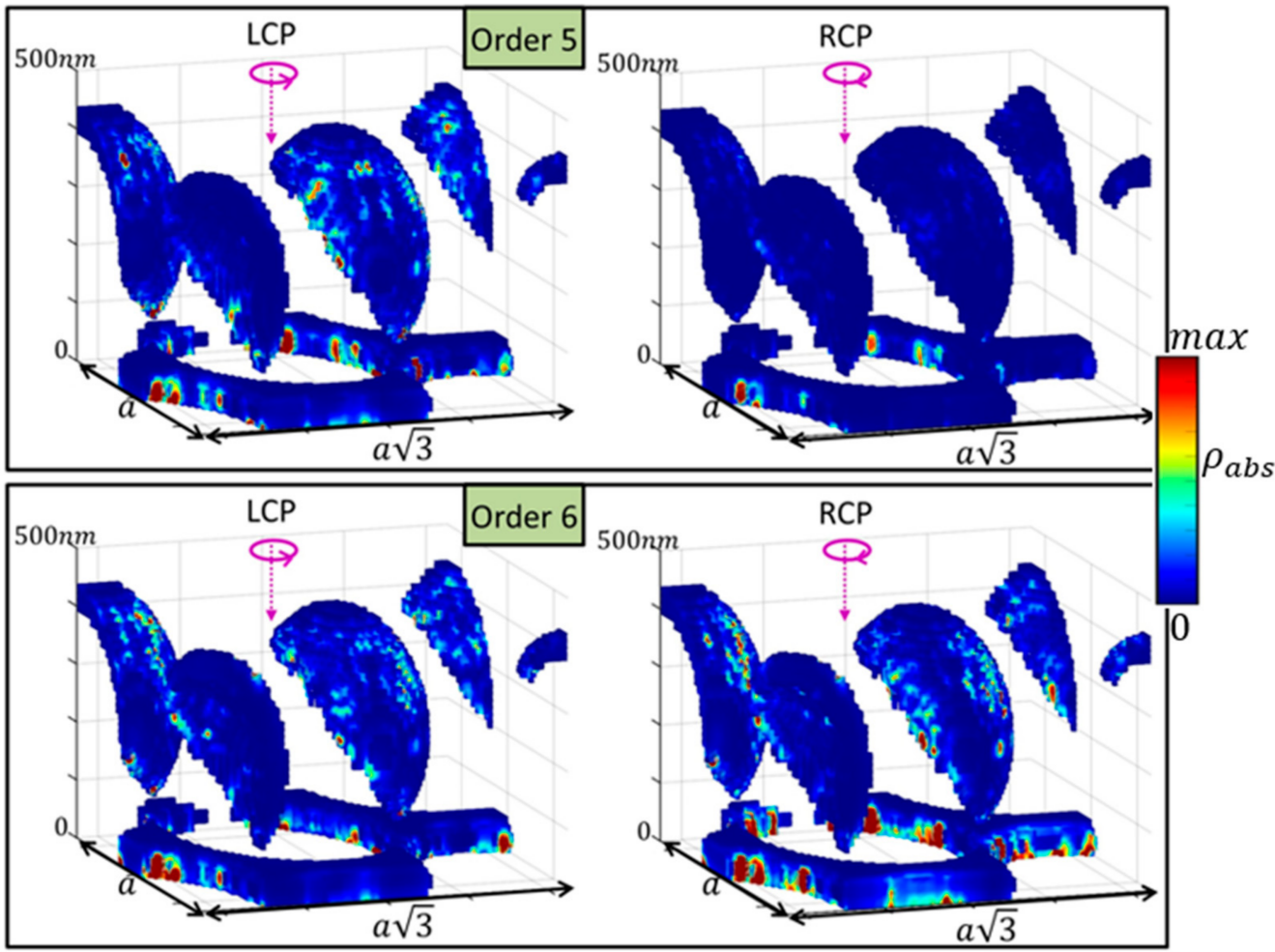

Figure 7. Distribution of the absorbed power in the unit cell when the metasurface is excited with LCP or RCP wavelength at $514 \mathrm{~nm}$; absorption for orders 5 and 6 shown in the top and bottom panels, respectively, while the color scale is kept constant.

\subsection{Determination of the Thermal Parameters of the Metasurface}

Among the various techniques, photothermal deflection (mirage effect) $[27,28,39]$ has been established as a noncontact method for optical and thermal property characterization. In particular, from the measurements of lateral deflection $\Phi_{x}$ vs. the pump-probe distance, it is possible to directly determine the thermal diffusivity by using, for example, the phase method [39,47-49]. According to such a method, the phase lag of the lateral deflection is $\varphi(x)=-x / \mu+\varphi_{0}=-x \sqrt{\pi f / D}+\varphi_{0}$, where sample thermal diffusivity $D$ is calculated simply from the linear slope of the $\mathrm{x}$ scan $(\mu=\sqrt{D / \pi f}$ is the thermal diffusion length). Unfortunately, this method can be applied to material thermal diffusivities larger than the air thermal diffusivity of $D_{\text {air }}=20 \mathrm{~mm}^{2} / \mathrm{s}$, with severe limitations for materials with a low thermal diffusivity, such as glasses (with $D=0.5 \mathrm{~mm}^{2} / \mathrm{s}$ ). To extend the method to these materials, a strong reduction in the probe beam height above the sample is recommended $(\mathrm{z}=10-20 \mu \mathrm{m})$, and/or the bouncing configuration should be used, sending the probe beam to the sample surface at a glazing angle (typically 1 degree) [50,51]. For these cases, the optothermal parameters can be worked out by fitting the lateral deflection (both amplitude and phase) with the complete theoretical model given by the following expression [50-54]:

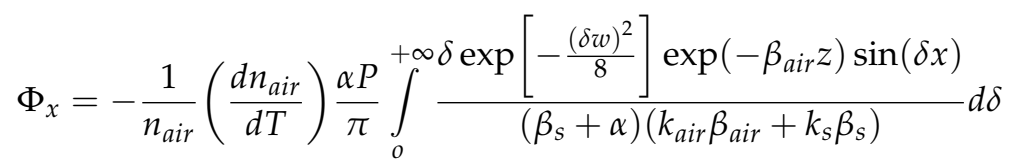

where $P$ is the optical power, $\alpha$ is the absorption coefficient, $\mathrm{w}$ is the pump beam spot size, $\beta_{\text {air }}=\sqrt{i \omega / D_{\text {air }}}, \beta_{s}=\sqrt{i \omega / D}$, and $k_{\text {air }}$ and $k_{s}$ are the air and sample thermal conductivities, respectively.

By analyzing both the PTD amplitude and the phase signals in the proximity of each heat source $(<0.3 \mathrm{~mm})$, the effective material thermal diffusion length, the material thermal diffusivity, and the effective spot size, can be calculated using Equation (9). These values 
are reported in Table 4 . The effective thermal diffusivity has been estimated to be about $D=0.6 \mathrm{~mm}^{2} / \mathrm{s}$ for all diffracted orders and light polarizations. This value is increased with respect to the typical glass diffusivity value of $D=0.5 \mathrm{~mm}^{2} / \mathrm{s}$ because of the silver and polystyrene surface layer. This demonstrates that, at a low modulation frequency of $36 \mathrm{~Hz}$, the effective thermal diffusivity is only weakly affected by the submicron metasurface which has a potentially higher thermally diffusive process, which could be specifically detected in the $\mathrm{MHz}$ range, but by using other experimental techniques [55-58]. Concerning the values of the effective spot sizes, one may notice that the values found for diffracted beams are larger with respect to the $0.09 \mathrm{~mm}$ found for the incident pump beam, in agreement with the elliptical enlargement shown in Figure 4 (the spot size is defined as the distance at which the Gaussian light intensity drops to $1 / \mathrm{e}^{2}$ of its maximum value). As an example, a good agreement between lateral deflection experimental data (amplitude and phase) and the theoretical expectations from Equation (9) is demonstrated in Figure 8. The best fit between the PDT data (symbols) and theory (continuous line) is shown for both amplitude and phase, and for $m=0$ and $m=2$. The probe beam height has been kept at $\mathrm{z}=30 \mu \mathrm{m}$.

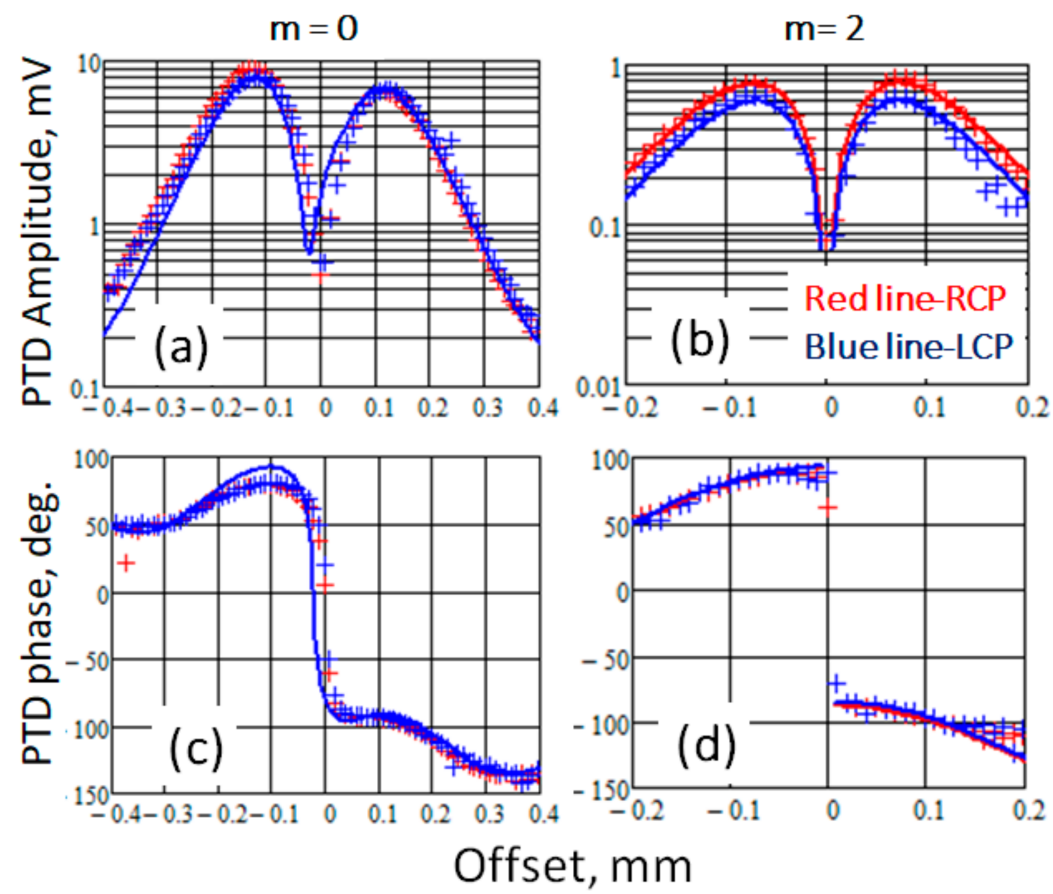

Figure 8. Lateral deflection data vs. offset: (a) amplitude for $m=0$; (b) amplitude for $m=2$; (c) phase for $m=0$; (d) phase for $m=2$. Continuous line is for the theoretical expectation from Equation (9). Symbols are for experimental data. For all figures, the red and blue symbols stand for RCP and LCP, respectively.

Table 4. Sample effective thermal diffusivity and beam spot size for all the diffracted beams as calculated from the best fit procedure of the PDT data with Equation (9).

\begin{tabular}{cccccccc}
\hline Quantity & Pump & \multicolumn{7}{c}{ Diffraction Order $\mathbf{m}$} & $\mathbf{5}$ & $\mathbf{6}$ \\
& $\mathbf{0}$ & $\mathbf{1}$ & $\mathbf{2}$ & $\mathbf{3}$ & $\mathbf{4}$ & $\mathbf{5}$ & 0.6 \\
\hline Diffusivity, $\mathrm{mm}^{2} / \mathrm{s}$ & 0.6 & 0.6 & 0.6 & 0.6 & 0.6 & 0.6 & 0.6 \\
Spot-size, $\mathrm{mm}$ & 0.09 & 0.09 & 0.14 & 0.17 & 0.09 & 0.14 & 0.17 \\
\hline
\end{tabular}

\section{Conclusions}

The photothermal deflection technique has been used as a sensitive tool to test chiral effects in diffractive metasurfaces. We have investigated one sample obtained by nanosphere lithography and asymmetrically covered in silver. At the wavelengths of an Ar pump beam, these materials exhibit chirality-governed diffraction orders. We used PDT data to local- 
ize the heat sources induced by the diffracted beams, retrieving the temperature profiles, and the effective thermal parameters of the material. The results are in good agreement with both thermal analyses and optical numerical simulations, thus creating new ways to optimize metasurfaces and for the use of PDT for the ultra-sensitive characterization.

Supplementary Materials: The following supporting information can be downloaded at: https: / / www.mdpi.com/article/10.3390/app12031109/s1, Video S1: behavior of the diffracted orders for the different wavelengths, when the metasurface is excited at normal incidence with RCP, Video S2: behavior of the diffracted orders for the quarter waveplate rotation when the metasurface is excited at normal incidence at $458 \mathrm{~nm}$, Video S3: behavior of the diffracted orders for the quarter waveplate rotation when the metasurface is excited at normal incidence at $514 \mathrm{~nm}$.

Author Contributions: Conceptualization, R.L.V., G.L., E.P., A.B., T.C., C.S. (Carlo Scian), G.M. and C.S. (Concita Sibilia); methodology, G.L., T.C., G.M.; software, E.P. and R.L.V.; validation, R.L.V., E.P.; formal analysis, T.C.; investigation, G.L.; data curation, R.L.V.; writing—original draft preparation, R.L.V. and E.P.; writing - review and editing, T.C., C.S. (Concita Sibilia) and G.M.; visualization E.P.; supervision, C.S. (Concita Sibilia). All authors have read and agreed to the published version of the manuscript.

Funding: This research received no external funding.

Institutional Review Board Statement: Not applicable.

Informed Consent Statement: Not applicable.

Data Availability Statement: Research data are not shared.

Acknowledgments: The authors acknowledge Marco Magi for the technical support.

Conflicts of Interest: The authors declare no conflict of interest.

\section{References}

1. Lewis, D.L.; Garrison, A.W.; Wommack, K.E.; Whittemore, A.; Steudler, P.; Melillo, J. Influence of environmental changes on degradation of chiral pollutants in soils. Nature 1999, 401, 898. [CrossRef]

2. Sanganyado, E.; Lu, Z.; Fu, Q.; Schlenk, D.; Gan, J. Chiral pharmaceuticals: A review on their environmental occurrence and fate processes. Water Res. 2017, 124, 527-542. [CrossRef] [PubMed]

3. Jeschke, P. Current status of chirality in agrochemicals. Pest Manag. Sci. 2018, 74, 2389-2404. [CrossRef] [PubMed]

4. Pasteur, L. On the Relations Crystalline Form, Chemical Composition and Direction of Polarization Rotatorie. Ann. Chim. Phys. $1848,24,442$.

5. Ploch-Jankowska, A.; Pentak, D.; Nycz, J.E. A Comprehensive Spectroscopic Analysis of the Ibuprofen Binding with Human Serum Albumin, Part II. Sci. Pharm. 2021, 89, 30. [CrossRef]

6. Rahman, N.; Khan, S. Circular Dichroism Spectroscopy: A Facile Approach for Quantitative Analysis of Captopril and Study of Its Degradation. ACS Omega 2019, 4, 4252-4258. [CrossRef]

7. Van Dijken, D.J.; Beierle, J.M.; Stuart, M.C.A.; Szymański, W.; Browne, W.R.; Feringa, B.L. Autoamplification of Molecular Chirality through the Induction of Supramolecular Chirality. Angew. Chem. Int. Ed. 2014, 53, 5073-5077. [CrossRef]

8. Toyofuku, K.; Alam, M.; Tsuda, A.; Fujita, N.; Sakamoto, S.; Yamaguchi, K.; Aida, T. Amplified Chiral Transformation through Helical Assembly. Angew. Chem. Int. Ed. 2007, 46, 6476-6480. [CrossRef]

9. Gaeta, M.; Randazzo, R.; Villari, V.; Micali, N.; Pezzella, A.; Purrello, R.; d'Ischia, M.; D’Urso, A. En Route to a Chiral Melanin: The Dynamic "From-Imprinted-to-Template" Supramolecular Role of Porphyrin Hetero-Aggregates during the Oxidative Polymerization of L-DOPA. Front. Chem. 2020, 8, 616961. [CrossRef] [PubMed]

10. Yashima, E.; Maeda, K.; Nishimura, T. Detection and Amplification of Chirality by Helical Polymers. Chem.-A Eur. J. 2004, 10, $42-51$.

11. Gaeta, M.; Raciti, D.; Randazzo, R.; Gangemi, C.M.A.; Raudino, A.; D'Urso, A.; Fragalà, M.E.; Purrello, R. Chirality enhancement of porphyrin supramolecular assembly driven by a template preorganization effect. Angew. Chem. Int. Ed. 2018, 57, 10656. [CrossRef]

12. Zhao, Y.; Askarpour, A.N.; Sun, L.; Shi, J.; Li, X.; Alù, A. Chirality detection of enantiomers using twisted optical metamaterials. Nat. Commun. 2017, 8, 14180. [CrossRef]

13. Valev, V.K.; Baumberg, J.J.; Sibilia, C.; Verbiest, T. Chirality and chiroptical effects in plasmonic nanostructures: Fundamentals, recent progress, and outlook. Adv. Mater. 2013, 25, 2517-2534. [CrossRef]

14. Esposito, M.; Tasco, V.; Cuscuna, M.; Todisco, F.; Benedetti, A.; Tarantini, I.; De Giorgi, M.; Sanvitto, D.; Passaseo, A. Nanoscale 3D Chiral Plasmonic Helices with Circular Dichroism at Visible Frequencies. ACS Photonics 2015, 2, 105-114. [CrossRef] 
15. Goerlitzer, E.S.A.; Puri, A.S.; Moses, J.J.; Poulikakos, L.V.; Vogel, N. The Beginner's Guide to Chiral Plasmonics: Mostly Harmless Theory and the Design of Large-Area Substrates. Adv. Opt. Mater. 2021, 9, 2100378. [CrossRef]

16. Kim, J.; Rana, A.S.; Kim, Y.; Kim, I.; Badloe, T.; Zubair, M.; Mehmood, M.Q.; Rho, J. Chiroptical Metasurfaces: Principles, Classification, and Applications. Sensors 2021, 21, 4381. [CrossRef] [PubMed]

17. Leahu, G.; Petronijevic, E.; Belardini, A.; Centini, M.; Sibilia, C.; Hakkarainen, T.; Koivusalo, E.; Rizzo Piton, M.; Suomalainen, S.; Guina, M. Evidence of Optical Circular Dichroism in GaAs-Based Nanowires Partially Covered with Gold. Adv. Opt. Mater. 2017, 5, 1601063. [CrossRef]

18. Benedetti, A.; Alam, B.; Esposito, M.; Tasco, V.; Leahu, G.; Belardini, A.; Li Voti, R.; Passaseo, A.; Sibilia, C. Precise detection of circular dichroism in a cluster of nano-helices by photoacoustic measurements. Sci. Rep. 2017, 7, 5257. [CrossRef]

19. Petronijevic, E.; Leahu, G.; Belardini, A.; Centini, M.; Li Voti, R.; Hakkarainen, T.; Koivusalo, E.; Rizzo Piton, M.; Suomalainen, S.; Guina, M.; et al. Photo-Acoustic Spectroscopy Reveals Extrinsic Optical Chirality in GaAs-Based Nanowires Partially Covered with Gold. Int. J. Thermophys. 2018, 39, 45. [CrossRef]

20. Petronijevic, E.; Leahu, G.; Li Voti, R.; Belardini, A.; Scian, C.; Michieli, N.; Cesca, T.; Mattei, G.; Sibilia, C. Photo-acoustic detection of chirality in metal-polystyrene metasurfaces. Appl. Phys. Lett. 2019, 114, 053101. [CrossRef]

21. Leahu, G.; Petronijevic, E.; Belardini, A.; Centini, M.; Li Voti, R.; Hakkarainen, T.; Koivusalo, E.; Guina, M.; Sibilia, C. Photoacoustic spectroscopy revealing resonant absorption of self-assembled GaAs-based nanowires. Sci. Rep. 2017, 7, 2833. [CrossRef] [PubMed]

22. Yamauchi, M.; Mawatari, K.; Hibara, A.; Tokeshi, M.; Kitamori, T. Circular Dichroism Thermal Lens Microscope for Sensitive Chiral Analysis on Microchip. Anal. Chem. 2006, 78, 2646-2650. [CrossRef]

23. Spaeth, P.; Adhikari, S.; Le, L.; Jollans, T.; Pud, S.; Albrecht, W.; Bauer, T.; Caldarola, M.; Kuipers, L.; Orrit, M. Circular Dichroism Measurement of Single Metal Nanoparticles Using Photothermal Imaging. Nano Lett. 2019, 19, 8934-8940. [CrossRef] [PubMed]

24. Spaeth, P.; Adhikari, S.; Dieter Baaske, M.; Pud, S.; Ton, J.; Orrit, M. Photothermal Circular Dichroism of Single Nanoparticles Rejecting Linear Dichroism by Dual Modulation. ACS Nano 2021, 15, 16277-16285. [CrossRef]

25. Kong, X.-T.; Khorashad, L.K.; Wang, Z.; Govorov, A.O. Photothermal Circular Dichroism Induced by Plasmon Resonances in Chiral Metamaterial Absorbers and Bolometers. Nano Lett. 2018, 18, 2001-2008. [CrossRef] [PubMed]

26. Miandashti, A.R.; Khorashad, L.K.; Kordesch, M.E.; Govorov, A.O.; Richardson, H.H. Experimental and Theoretical Observation of Photothermal Chirality in Gold Nanoparticle Helicoids. ACS Nano 2020, 14, 4188-4195. [CrossRef] [PubMed]

27. Boccara, A.C.; Fournier, D.; Jackson, W.; Amer, N.M. Sensitive photothermal deflection technique for measuring absorption in optically thin media. Opt. Lett. 1980, 5, 377. [CrossRef]

28. Bertolotti, M.; Voti, R.L. A note on the history of photoacoustic, thermal lensing, and photothermal deflection techniques. J. Appl. Phys. 2020, 128, 230901. [CrossRef]

29. Leahu, G.; Voti, R.L.; Sibilia, C.; Bertolotti, M.; Golubev, V.; Kurdyukov, D.A. Study of thermal and optical properties of SiO2/GaN opals by photothermal deflection technique. Opt. Quantum Electron. 2007, 39, 305-310. [CrossRef]

30. Dickmann, W.; Dickmann, J.; Feilong Bruns, F.; Kroker, S. Key, Signal contributions in photothermal deflection spectroscopy. J. Appl. Phys. 2019, 126, 025106. [CrossRef]

31. Morawiec, S.; Holovský, J.; Mendes, M.J.; Müller, M.; Ganzerová, K.; Vetushka, A.; Ledinský, M.; Priolo, F.; Fejfar, A.; Crupi, I. Experimental quantification of useful and parasitic absorption of light in plasmon-enhanced thin silicon films for solar cells application. Sci. Rep. 2016, 6, 22481. [CrossRef] [PubMed]

32. Hanifi, D.A.; Bronstein, N.D.; Koscher, B.A.; Nett, Z.; Swabeck, J.K.; Takano, K.; Schwartzberg, A.M.; Maserati, L.; Vandewal, K.; van de Burgt, Y.; et al. Redefining near-unity luminescence in quantum dots with photothermal threshold quantum yield. Science 2019, 363, 1199. [CrossRef]

33. Chima, H.; Shiokawa, N.; Seto, K.; Takahashi, K.; Hirosaki, N.; Kobayashi, T.; Tokunaga, E. Thermal Relaxation Spectra for Evaluating Luminescence Quantum Efficiency of CASN:Eu2+ Measured by Balanced-Detection Sagnac-Interferometer Photothermal Deflection Spectroscopy. Appl. Sci. 2020, 10, 1008. [CrossRef]

34. Leahu, G.; Petronijevic, E.; Li Voti, R.; Belardini, A.; Cesca, T.; Mattei, G.; Sibilia, C. Diffracted Beams from Metasurfaces: High Chiral Detectivity by Photothermal Deflection Technique. Adv. Opt. Mater. 2021, 9, 2100670. [CrossRef]

35. Cesca, T.; Michieli, N.; Kalinic, B.; Balasa, I.G.; Rangel-Rojo, R.; Reyes Esqueda, J.A.; Mattei, G. Bidimensional ordered plasmonic nanoarrays for nonlinear optics, nanophotonics and biosensing applications. Sci. Semicond. Process. 2019, 92, 2. [CrossRef]

36. Petronijevic, E.; Belardini, A.; Leahu, G.; Cesca, T.; Scian, C.; Mattei, G.; Sibilia, C. Circular dichroism in low-cost plasmonics: 2D arrays of nanoholes in silver. Appl. Sci. 2020, 10, 1316. [CrossRef]

37. Petronijevic, E.; Belardini, A.; Cesca, T.; Scian, C.; Mattei, G.; Sibilia, C. Rich, Near-infrared chiral behavior in diffractive metasurfaces. Phys. Rev. Appl. 2021, 16, 014003. [CrossRef]

38. Petronijevic, E.; Ghahri, R.; Sibilia, C. Plasmonic Elliptical Nanohole Arrays for Chiral Absorption and Emission in the NearInfrared and Visible Range. Appl. Sci. 2021, 11, 6012. [CrossRef]

39. Jackson, W.B.; Amer, N.M.; Boccara, A.C.; Fournier, D. Photothermal deflection spectroscopy and detection. Appl. Opt. 1981, 20, 1333. [CrossRef] [PubMed]

40. Lumerical Solutions, Inc. Available online: https://www.lumerical.com/tcad-products/fdtd (accessed on 31 December 2021).

41. Tomoda, M.; Voti, R.L.; Matsuda, O.; Wright, O.B. Tomographic reconstruction of picosecond acoustic strain propagation. Appl. Phys. Lett. 2007, 90, 041114. [CrossRef] 
42. Glorieux, C.; Voti, R.L.; Thoen, J.; Bertolotti, M.; Sibilia, C. Photothermal depth profiling: Analysis of reconstruction errors. Inverse Probl. 1999, 15, 1149. [CrossRef]

43. Voti, R.L. Optimization of transparent metal structures by genetic algorithms. Rom. Rep. Phys. 2012, 64, 446.

44. Voti, R.L.; Liakhou, G.L.; Paoloni, S.; Sibilia, C.; Bertolotti, M. Thermal wave physics. J. Optoelectron. Adv. Mater. $2001,3,779$.

45. Bertolotti, M.; Liakhou, G.L.; Voti, R.L.; Sibilia, C. Thermal characterization by photodeflection method. J. Therm. Anal. 1996, 47, 51. [CrossRef]

46. Bertolotti, M.; Liakhou, G.L.; Voti, R.L.; Wang, R.P.; Sibilia, C.; Syrbu, A.V.; Yakovlev, V.P. An experimental and theoretical analysis of the temperature profile in semiconductor laser diodes using the photodeflection technique. Meas. Sci. Technol. 1995, 6, 1278. [CrossRef]

47. Bertolotti, M.; Voti, R.L.; Leahu, G.; Sibilia, C. On the photodeflection method applied to low thermal diffusivity measurements. Rev. Sci. Instrum. 1993, 64, 1576. [CrossRef]

48. Bertolotti, M.; Voti, R.L.; Michelotti, F.; Liakhou, G.; Sibilia, C. Method for thermal diffusivity measurements based on photothermal deflection. J. Appl. Phys. 1993, 74, 7078. [CrossRef]

49. Bertolotti, M.; Dorogan, V.; Liakhou, G.L.; Voti, R.L.; Paoloni, S.; Sibilia, C. New photothermal deflection method for thermal diffusivity measurement of semiconductor wafers. Rev. Sci. Instrum. 1997, 68, 1521. [CrossRef]

50. Bertolotti, M.; Liakhou, G.L.; Voti, R.L.; Paoloni, S.; Sibilia, C. Analysis of the photothermal deflection technique in the surface reflection scheme: Theory and experiment. J. Appl. Phys. 1998, 83, 966. [CrossRef]

51. Bertolotti, M.; Liakhou, G.L.; Voti, R.L.; Paoloni, S.; Sibilia, C. Probe-beam incidence angle-effects on thermal diffusivity measurement by photothermal deflection technique. Appl. Phys. B 1998, 67, 641. [CrossRef]

52. Larciprete, M.C.; Sibilia, C.; Paoloni, S.; Leahu, G.; Voti, R.L.; Bertolotti, M.; Scalora, M.; Panajotov, K. Thermally induced transmission variations in ZnSe/MgF2 photonic band gap structures. J. Appl. Phys. 2002, 92, 2251. [CrossRef]

53. Cesarini, G.; Leahu, G.; Grilli, M.L.; Sytchkova, A.; Sibilia, C.; Li Voti, R. Optical and photoacoustic investigation of AZO/Ag/AZO transparent conductive coating for solar cells. Phys. Status Solidi C 2016, 13, 998. [CrossRef]

54. Lamastra, F.R.; Grilli, M.L.; Leahu, G.; Belardini, A.; Li Voti, R.; Sibilia, C.; Salvatori, D.; Cacciotti, I.; Nanni, F. Diatom frustules decorated with zinc oxide nanoparticles for enhanced optical properties. Nanotechnology 2017, 28, 375704. [CrossRef] [PubMed]

55. Tomoda, M.; Wright, O.B.; Voti, R.L. Nanoscale thermoelastic probing of megahertz thermal diffusion. Appl. Phys. Lett. 2007, 91, 071911. [CrossRef]

56. Kashiwada, S.; Matsuda, O.; Baumberg, J.J.; Voti, R.L.; Wright, O.B. In situ monitoring of the growth of ice films by laser picosecond acoustics. J. Appl. Phys. 2006, 100, 073506. [CrossRef]

57. Rizzi, G.; Benetti, G.; Giannetti, C.; Gavioli, L.; Banfi, F. Analytical model of the acoustic response of nanogranular films adhering to a substrate. Phys. Rev. B 2021, 104, 035416. [CrossRef]

58. Benetti, G.; Banfi, F.; Cavaliere, E.; Gavioli, L. Mechanical properties of nanoporous metallic ultrathin film: A paradigmatic case. Nanomaterials 2021, 11, 3116. [CrossRef] 